\title{
Oral Status of Children with Diabetes in the Hospital of Mali: 79 Observations
}

\author{
Niang $A^{1 *}$, Ba $B^{2}$, Diawara $0^{3}$, Ba $M^{2}$, Sacko $K^{3}$, Wane Togo $A^{4}$, Kane $\mathrm{AST}^{1}$, Koita $\mathrm{H}^{2}$, Toure $\mathrm{A}^{2}$, Sangare $\mathrm{B}^{5}$ and Traore \\ $\mathrm{AS}^{4}$
}

${ }^{1}$ Pediatric Dentistry Service, CHU CNOS, Mali

${ }^{2}$ Oral Surgery Service, $\mathrm{CHU}$ CNOS, Mali

${ }^{3}$ Department of Periodontology, CHU CNOS, Mali

${ }^{4}$ Department of Internal Medicine and Endocrinology of the Hospital, Mali

${ }^{5}$ Service of Conservative Dentistry and Endodontics, CHU CNOS, Mali

*Corresponding author: Niang Amsalla, Service of Pédodontie, CHU CNOS of Bamako, BP 2067 Republic of Mali

Submission: 眥January 31, 2018; Published: 非 February 23, 2018

\begin{abstract}
Introduction: Diabetes is a condition characterized by chronic hyperglycemia which may be due decreased insulin levels as well as due to receptors. Unbalanced, it can lead to severe complications. Periodontal disease is one of the complications of unbalanced diabetes. This bacterial disease destroys the tissues that support teeth and causes their loss.

Objective: The objective of this study was to describe the epidemiological and clinical characteristics of the oral diseases observed in diabetic children followed at the Mali hospital.

Materials and methods: We conducted a six-month cross-sectional study based on the observation of the periodontal condition of 79 children with diabetes aged 6 to 15 years followed at the Mali Hospital. Brushing was considered normal when a child was brushing vertically. The data were collected from a survey sheet prepared for the occasion, a follow-up notebook, registers (consultation and hospitalization), entered on the Epi info 3.5.3 software, and Excel from the Microsoft Starter 2007 software. Statistical calculations were carried out with chi- 2 of Pearson with an alpha risk $\leq 0.05$.

Results: We recorded 67 cases of periodontal disease, $84.81 \%$. The male sex was represented with $51.89 \%$ of cases and a sex ratio of 1.07 . The age group 12-15 years was represented with $65.6 \%$ of the cases (Table 1). Patients were students / students in $88.6 \%$ of the cases (Table 2).

All our patients had type 1 diabetes and 1 to 5 years of age in $72.15 \%$ of cases. Fifty-nine patients had blood glucose levels above $1.26 \mathrm{~g} / \mathrm{l}$, i.e., $76.8 \%$ of the cases (Table $3 \& 4$ ). Forty-six of our patients had glycated hemoglobin $>10 \%$ or $57.7 \%$ (Table 5), i.e., a very high risk of complications. The diseases encountered in our patients were retinopathy problems, followed by gastritis / ulcers with $34 \%$ and $28 \%$ respectively (Table 6). Children had poor brushing technique in $96.20 \%$ (Table 7) of the cases and did not know the relationship between diabetes and oral disease in 93.67\% (Table 8 \& 9) cases. They had a low plaque index (low oral hygiene) in $8.8 \%$ of cases (Table $10 \& 11$ ) and severe gingival inflammation in $6.33 \%$ of cases (Table 12). Children had $74.68 \%$ malocclusion, $29.11 \%$ halitosis and $56.96 \%$ dry mouth.
\end{abstract}

Conclusion: This study showed a high frequency of periodontal disease in our diabetic children population. Prevention, promotion of oral health and early detection will improve the health and quality of life of these children; Hence the need to integrate the odontologist into the multidisciplinary team of diabetic children.

Keywords: Children; Diabetes; Gingival inflammation; Plaque index; Affections; Oral

\section{Introduction}

Table 1: Workforce distribution by age range.

\begin{tabular}{|c|c|c|}
\hline Age Range (years) & Effective & Frequency (\%) \\
\hline 06-Aug & 10 & 27,3 \\
\hline 09-Nov & 5 & 7,1 \\
\hline Dec-15 & 64 & 65,6 \\
\hline Total & 79 & 100,00 \\
\hline
\end{tabular}

Table 2: Distribution by level of study.

\begin{tabular}{|c|c|c|}
\hline Level of Study & Effective & Frequency (\%) \\
\hline Not enrolled & 9 & 11,4 \\
\hline Primary school & 67 & 79,7 \\
\hline Secondary school & 7 & 8,9 \\
\hline Total & 79 & 100,00 \\
\hline
\end{tabular}


Table 3: Breakdown of the workforce by BMI.

\begin{tabular}{|c|c|c|}
\hline BMI & Effective & Frequency (\%) \\
\hline$<18,5$ & 37 & 46,8 \\
\hline $18,5-24,5$ & 40 & 50,6 \\
\hline $24,9-29,9$ & 2 & 2,5 \\
\hline Total & 79 & 100,00 \\
\hline
\end{tabular}

Table 5: Result of glycated hemoglobin.

\begin{tabular}{|c|c|c|c|c|c|}
\hline HbA1c & Our Results & State of Equilibrium & Risk of Complications & Effective & Frequency(\%) \\
\hline$<7 \%$ & $4,2 / 6,9 \%$ & Very good & Little or no risk & 15 & 19,4 \\
\hline $7-8 \%$ & $7,1 / 7,3 \%$ & Way & Low but existing & 4 & 5,1 \\
\hline $8-10 \%$ & $8,1 / 9,8 \%$ & Imbalance & Important & 14 & 17,8 \\
\hline$>10 \%$ & $10,1 / 15 \%$ & Very unbalanced & Very important & 46 & 57,7 \\
\hline \multicolumn{7}{|r|}{} & Total & 79 & 100,00 \\
\hline
\end{tabular}

Table 6: Distribution by complications of diabetes.

\begin{tabular}{|c|c|c|}
\hline Complications of Diabetes & Effective & Frequency(\%) \\
\hline Acid Ketosis & 9 & 11,39 \\
\hline Coma hypoglycemic & 1 & 1,27 \\
\hline Gastritis / Ulcer & 14 & 17,72 \\
\hline Pulmonary Diseases & 4 & 5,06 \\
\hline RAA & 4 & 5,06 \\
\hline Retinopathy & 17 & 21,53 \\
\hline No complications & 30 & 37,97 \\
\hline
\end{tabular}

Table 7: Breakdown of the population according to the frequency of brushing.

\begin{tabular}{|c|c|c|}
\hline Number of Brushing & Effective & Frequency (\%) \\
\hline 1 time & 33 & 42,7 \\
\hline 2 times & 37 & 47,4 \\
\hline 3 times & 5 & 6,3 \\
\hline More than 3 times & 3 & 3,8 \\
\hline Total & 79 & 100,00 \\
\hline
\end{tabular}

Table 8: Distribution according to brushing technique.

\begin{tabular}{|c|c|c|}
\hline Brushing Technique & Effective & Frequency(\%) \\
\hline Good & 3 & 3,8 \\
\hline Poor & 76 & 96,2 \\
\hline Total & 79 & 100,00 \\
\hline
\end{tabular}

Table 9: Distribution according to knowledge of the relationship between diabetes and oral diseases.

\begin{tabular}{|c|c|c|}
\hline $\begin{array}{c}\text { Knowledge of the Relationship between } \\
\text { Diabetes and Oral Diseases }\end{array}$ & Effective & $\begin{array}{c}\text { Frequency } \\
\text { (\%) }\end{array}$ \\
\hline No & 74 & 93,67 \\
\hline Yes & 5 & 6,33 \\
\hline Total & 79 & 100,00 \\
\hline
\end{tabular}

Table 10: Percentage distribution of patients by CAD teeth.

\begin{tabular}{|c|c|}
\hline CAD Tooth & Effective \\
\hline Decayed teeth & 284 \\
\hline Teeth absent & 4 \\
\hline Filled teeth & 9 \\
\hline
\end{tabular}

Table 4: Breakdown of the workforce by blood glucose level.

\begin{tabular}{|c|c|c|}
\hline Blood Sugar Levels $(\mathbf{g} / \mathbf{l})$ & Effective & Frequency (\%) \\
\hline $0,30-0,70$ & 2 & 2,6 \\
\hline $0,70-1,26$ & 18 & 20,6 \\
\hline $1,27-5,33$ & 59 & 76,8 \\
\hline Total & 79 & 100,00 \\
\hline
\end{tabular}

Table 11: Percentage distribution of patients by plate index.

\begin{tabular}{|c|c|c|}
\hline Plate Number & Effective & Frequency (\%) \\
\hline Excellent (0) & 5 & 6,33 \\
\hline Good (0.1-0.9) & 24 & 30,38 \\
\hline Average (1-1.9) & 43 & 54,43 \\
\hline Low (2-3) & 7 & 8,86 \\
\hline Total & 79 & 100,00 \\
\hline
\end{tabular}

Table 12: Percentage distribution of patients by gingival index.

\begin{tabular}{|c|c|c|}
\hline Gingival Index & Effective & Frequency (\%) \\
\hline No inflammation (0) & 11 & 13.92 \\
\hline Light Inflammation (0,1-0,9) & 30 & 37.98 \\
\hline Medium Inflammation(1-1,9) & 33 & 41,77 \\
\hline Severe inflammation (2-3) & 5 & 6,33 \\
\hline Total & 79 & 100,00 \\
\hline
\end{tabular}

Diabetes is a condition characterized by chronic hyperglycemia resulting from a deficiency of insulin secretion. Unbalanced, it can lead to severe complications. Periodontal disease is one of the complications of unbalanced diabetes. This bacterial disease destroys the tissues that support teeth and causes their loss. Prevention of dental diseases can have a beneficial effect on the balance of diabetes and the quality of life of the affected individuals [1]. Globally, an estimated 422 million people are living with diabetes in 2014, compared with 108 million in 1980. The global (age standardized) prevalence of diabetes has almost doubled since 1980, from $4.7 \% 8.5 \%$ [2].

Diabetes mellitus affects virtually all tissues and organs of the body, including those in the oral cavity, manifesting with several complications. These complications may include oral infections, and precancerous oral infections [3]. They are observable in children due to altered cellular immunity.

In Mali in 1996, studies in two national hospitals in Bamako showed that diabetes was the second leading cause of hospitalization and $40 \%$ of internal medicine. The prevalence of diabetes today exceeds $9.3 \%$ of the Malian population [4]. 
The objective of our study was to describe the epidemiological and clinical characteristics of the oral diseases observed in diabetic children followed at the hospital of Mali.

\section{Material and Methods}

We carried out a cross-sectional epidemiological study based on oral observation of children with diabetes followed at the Mali hospital in Bamako over a period of four (4) months from March 1 to June 30,2015 , on a sample of 79 patients.

In this study we administered a medical questionnaire, followed by an oral examination. Clinical characteristics of diabetes were collected from follow-up diaries, reference sheets, consultation and hospitalization records. The population concerned was the diabetic children followed in the Department of Medicine and Endocrinology of the Mali Hospital. We used the Green and Vermillon Simplified Oral Hygiene Index (IHOS) and WILKINS to assess the quality of oral hygiene. The gingival index of LOË and SILNESS for gingival inflammation and the CAD / D index for dental status. Dental mobility was assessed by the MUHLEMANN index [5]. Statistical calculations were performed with Pearson chi-2 with an alpha risk $\leq 0.05$.

\section{Results}

We recorded 67 cases of periodontal disease, a frequency of $84.81 \%$. The male sex accounted for $51.89 \%$ of cases for a sex ratio of 1.07 . The age group 12-15 years was the most represented with $65.6 \%$ of the cases. The majority of the patients were students / students, or $88.6 \%$ of the cases.

All our patients had type 1 diabetes for 1 to 5 years in $72.15 \%$ of cases. Fifty - nine (59) patients had blood glucose levels above $1.26 \mathrm{~g} / \mathrm{l}$, or $76.8 \%$ of the cases. Forty-six (46) patients had glycated hemoglobin $>10 \%$ or $57.7 \%$. The diseases observed in our patients were problems of retinopathies and gastritis / ulcers with respectively $34 \%$ and $28 \%$ of the cases.

All children brushed their teeth either $100 \%$ of the cases for a twice daily frequency of brushing (47.4\%). However, a poor technique of brushing was found in $96.20 \%$ of cases and the majority of children were unaware of the relationship between diabetes and oral diseases, $93.67 \%$ of cases. A low plaque index (poor oral hygiene) was observed in $8.8 \%$ of cases for severe gingival inflammation in $6.33 \%$ of cases. Children with diabetes had a malocclusion in $74.6 \%$ of the cases, $29.1 \%$ had halitosis and $56.9 \%$ had dry mouth. The gingival index was mean in $40.5 \%$ of the cases and they had angular cheilitis, glossitis and palliative lesions respectively in $22.78 \% ; 20.25 \%$ and $18.98 \%$. Diabetic children did not consult with Dental Surgeon in $76.0 \%$ of cases. We found no statistical link between the socio-demographic variables and the various indices.

\section{Discussion}

In our study we recorded an overall frequency of $84.81 \%$ of cases of periodontal disease. In a study conducted in Mali, Sidibé [6] reported $80 \%$ of the cases, which is supported by other similar studies in Senegal 97.5\% [7], Essama et al. [8]. In Cameroon reported $87,80 \%$ of cases of gingivitis and $12,20 \%$ of periodontitis).

The male sex was the most represented with $51.89 \%$ and a sex ratio 1.07 . The most represented age group was that of 12 to 15 years, $65.6 \%$ of the cases. According to socio-professional activity, students accounted for $88.6 \%$ of the cases. In Mali, Togo [9] and Coulibaly [10] respectively reported a male predominance of $51.4 \%$ and $55.3 \%$ of cases. In Senegal, Thiam [7] reported 57.5\% of male cases and Thiam [11] reported an age group of $13-15$ years $(62 \%$ of cases).

From the point of view of the diabetic clinical characteristics all our patients had the type 1 and a seniority of 1 to 5 years in $72.1 \%$ of the cases. Fifty-nine patients (76.8\%) had blood glucose levels greater than or equal to $1.26 \mathrm{~g} / \mathrm{l}$ (hyperglycemic), and had glycated hemoglobin $>10 \%$ in $57.7 \%$ of the cases. of diabetes. Our patients did not know the relationship between diabetes and oral disease in $93.67 \%$ of cases.

Coulibaly [10] reported in his study a blood glucose level greater than or equal to $84.6 \%$ of the cases. Thiam [7] reported a 4-year seniority in diabetes, $67 \%$ of cases. In France, Ternois et al. [12] reported in 74 diabetic children aged 1 to 17.5 years a very unbalanced glycated hemoglobin of 8 to $10 \%$ or $>10 \%$, or $54 \%$ of the cases. They reported little information about diabetes and oral health in $39 \%$ of children.

Peyraud et al. [13] reported a diabetes mellitus for less than five years, average glycated hemoglobin of $8.0 \pm 0.97 \%$ and an age of $5.92 \pm 2.75$ years. The children in their study had an "acceptable" level of knowledge about oral health / diabetes links [13]. Choleau et al. [14] reported in their study an age of diabetes of $4.9 \pm 3.6$ years and mean $\mathrm{HbA} 1 \mathrm{c}$ of $8.3 \pm 1.5$ in children.

In our study, children had poor oral hygiene in $8.8 \%$ and a severe gingival index in $6.33 \%$. They had malocclusion in $74.6 \%$ (however we did not investigate the link between this condition and periodontal disease), halitosis in $29.1 \%$ and dryness in the mouth in $56.9 \%$ of cases.

Bissong et al. [3] reported in Cameroonian diabetic patients $23.5 \%$ of gingivitis; $24.8 \%$ periodontitis; $19.5 \%$ of dental caries and $21.5 \%$ of oral candidacies. Thiam [7] reported an average gingival inflammation in $72.5 \%$ of cases and average oral hygiene in $77.5 \%$ of cases. Peyraud et al. [13] reported an average CAD score of $0.80 \pm 1.38$ and an average gingival index of $0.50 \pm 0.54$ with better oral hygiene.

No statistical link between the periodontal status (plaque index and gingival index) and sex, age group and age of diabetes.

\section{Conclusion}

The study revealed a high frequency of oral diseases in children with diabetes. Awareness-raising campaigns and the promotion of oral health for this segment of the population are needed. It is necessary to integrate the Surgeon-Dentist into the 
multidisciplinary care team in order to improve the health and quality of life of the children.

\section{References}

1. Rochereau T, Ley A (2008) Is the management of oral care for people with diabetes appropriate? Operation of the ESPS 2008 survey, Health Economics Issues no. 185

2. WHO (2016) World diabetes report.

3. Bissong M, Azodo CC, Agbor MA, Nkuo-Akenji T, Fon PN (2015) Ora health status of diabetes mellitus patients in southwest Cameroon. Odontostomatol Trop 38(150): 49-57.

4. Beran D. The management of diabetes in Mali.

5. Sow A (2005) Gingival bleeding: assessment in a Dakar population (about a survey of 124 patients). Thesis Chir Dent, Dakar, Senegal, p. 14

6. Sidibe B (2014) Evaluation of the periodontal treatment needs of diabetic patients of the national center of fight against diabetes of Bamako. Thesis Chir Dent, Bamako, Mali.
7. Thiam M (2005) Contribution to the study of the oral health of diabetic children. Thesis Chir Dent, Dakar, Senegal, p. 24.

8. Essama EB, Bell NW, Kouotou MJS, Choukem SP (2013) Evaluation of the oral health of Cameroonian diabetic patients Health Sci Dis 14(3): 1-5.

9. Togo AD (2010) Clinical and therapeutic epidemiological aspects of diabetes in children and adolescents. Thesis de Med, Bamako, Mali, p. 5.

10. Coulibaly F (2014) The problem of insulin therapy in type 1 diabetics of 5 to 25 years in the department of medicine and endocrinology at the hospital of Mali Thèse Med Bamako, Mali.

11. Thiam F (2006) Diabetes and Periodontal Diseases. Case-control study in children aged -15 years. Thesis chir tooth, Dakar, Senegal, p. 9.

12. Ternois M (2010) Diabetes type 1: Adults and adolescents -the same oral condition? $33^{\text {rd }}$ Diabetology meeting, Le Touquet, France.

13. Peyrau C (2012) Oral health in children with type 1 diabetes: study in a group of 40 children. Diabetes Metab 38: A130- A132.

14. Choleau C (2016) Study of insulin injection technique and feelings of young people with type 1 diabetes: impact on educational follow-up. Elsevier Masson SAA 2016 Diabetes Metab 2012(3): A130-A132.

\section{Your subsequent submission with Crimson Publishers} will attain the below benefits

- High-level peer review and editorial services

- Freely accessible online immediately upon publication

- Authors retain the copyright to their work

- Licensing it under a Creative Commons license

- Visibility through different online platforms

- Global attainment for your research

- Article availability in different formats (Pdf, E-pub, Full Text)

- Endless customer service

- Reasonable Membership services

- Reprints availability upon request

- One step article tracking system 